\title{
ACTIVACIÓN Y PUESTA EN VALOR DE BIENES CULTURALES/ PATRIMONIALES DE LA PENÍNSULA DE PUNTA DEL ESTE, URUGUAY: PRODUCCIÓN DE MATERIALES MULTIMEDIA CON FINES TURÍSTICOS
}

\author{
Gabriela Campodónico* \\ Mariciana Zorzi*, \\ Facundo Bianchi ${ }^{* * *}$
}

\section{RESUMEN}

Este trabajo tiene como objetivo presentar los resultados de un proyecto de activación y puesta en valor de bienes culturales y de la memoria, llevado adelante en el municipio de Punta del Este, Uruguay. La investigación comenzó en el ańo 2016, a partir del trabajo conjunto de docentes y estudiantes del Área de Estudios Turísticos del Centro Universitario Regional Este y de la Comisión de Cultura y Patrimonio del Municipio. En el año 2020 se logró producir materiales de difusión de los bienes culturales y sus memorias, a través de la creación de un mapa multimedia, que contiene fragmentos de audios, textos y cortometrajes que aluden a los bienes identificados. Se espera que este trabajo pueda contribuir a la diversificación de la oferta de actividades de ocio.

Palabras clave: turismo, bienes culturales, multimedia, Punta del Este.

\author{
ACTIVATION AND ENHANCEMENT OF CULTURAL/PATRIMONIAL ASSETS \\ IN THE PENINSULA OF PUNTA DEL ESTE, URUGUAY: PRODUCTION \\ OF MULTIMEDIA MATERIALS FOR TOURISM
}

\section{Abstract}

This work aims to present the results of a project intended to activate and enhance cultural assets and memory, conducted in the Municipality of Punta del Este, Uruguay. The research began in 2016, based on the joint work of teachers and students from the Tourism Studies Area of the Eastern Regional University Center and the Municipality's Culture and Heritage Commission. In the year 2020 we were able to produce materials for the diffusion of cultural assets and their memories, through the creation of a multimedia map containing fragments of audio records, texts and short films that allude to the identified assets. This work is expected to contribute to diversifying the offer of leisure activities.

KEYWORds: tourism, cultural assets, multimedia, Punta del Este. 


\section{INTRODUCCIÓN}

La ciudad de Punta del Este, ubicada en el litoral este de Uruguay, es uno de los principales destinos turísticos de América Latina. El crecimiento demográfico y el desarrollo económico de la región están históricamente relacionados con su proximidad a las costas del océano Atlántico y del Río de la Plata. La costa del departamento ha sido el eje sobre el que gira la actividad turística. El modelo predominante es el que se describe en la bibliografía como «turismo de sol y playa».

A partir de los años 70 el balneario experimentó el primer «boom» inmobiliario con la construcción de torres y edificios (Trochón, 2017). Ese proceso de desarrollo inmobiliario también trajo como consecuencia el cambio del paisaje y la cotidianidad en Punta del Este. Esa transformación fomentó la reivindicación de la preservación de determinados lugares por parte de personas, grupos e instituciones, como es el caso del grupo "Amigos del Faro", surgido en 1986, y de un grupo de vecinos, formado principalmente por exalumnos de la escuela pública ${ }^{\circ}{ }^{\circ} 5$, que lograran la preservación del edificio de la exestación de expendio de combustible de Ancap, en la emblemática calle Gorlero.

Desde la sociedad local, las necesidades partieron a través de una serie de inquietudes y demandas relativas a la elaboración de productos turísticos concretos vinculados al espacio urbano, el patrimonio y la memoria de Punta del Este. La Comisión de Cultura y Patrimonio de la Alcaldía de Punta del Este requirió la colaboración de la Universidad para trabajar en el registro de bienes patrimoniales de la península. El equipo de trabajo ha realizado, además de la investigación bibliográfica y observación en variados contextos, entrevistas en profundidad a antiguos habitantes de la península. Estas entrevistas (21) estuvieron centradas en el registro de narrativas asociadas a la historia de la ciudad, a la identificación de lugares valorados por los entrevistados y en las percepciones del lugar en el presente.

Las entrevistas fueron sistematizadas y se crearon categorías y subcategorías de análisis, tales como acontecimientos, lugares, personas, prácticas, saberes y oficios. Los bienes identificados fueron georreferenciados en un mapa y se comenzó un trabajo de búsqueda de información, tal como ubicación geográfica, estado de conservación, reseña histórica, narrativas asociadas, entre otros aspectos.

En ese proceso, surgieron reflexiones y cuestionamientos que luego fueron compartidos en ponencias y artículos (Campodónico, Zorzi y Bianchi, 2019): ¿̨hay espacio para la memoria y la historia de Punta del Este en la identidad turística de este balneario? Algunos de los lugares del pasado como restaurantes y hoteles ya no existen físicamente, ¿qué nos ofrece la tecnología actual en relación con la puesta en

* E-mail: gcampod@yahoo.com, Área de Estudios Turísticos, Centro Universitario Regional del Este, Universidad de la República.

**E-mail: mari.zorzi@gmail.com, Área de Estudios Turísticos, Centro Universitario Regional del Este, Universidad de la República.

*** E-mail: facundo.bianchi@cure.edu.uy, Área de Estudios Turísticos, Centro Universitario Regional del Este, Universidad de la República. 
valor de la faceta inmaterial de esos lugares valorados por los antiguos moradores? ¿Qué metodologías pueden facilitar la incorporación de investigaciones científicas en la elaboración de experiencias turísticas basadas en el patrimonio local? ¿Estarían los visitantes de Punta del Este interesados en conocer su historia y memoria?

Luego de un proceso de búsqueda y reflexión, en el año 2020, con el apoyo del Departamento de Ciencias Sociales y Humanas y del Municipio de Punta del Este se elaboraron materiales multimedia con el fin de disponibilizar al público (comunidad local y visitantes) los resultados de la investigación, y activar turísticamente los bienes identificados. Estos productos son una serie de videos documentales cuyos protagonistas son antiguos residentes, trabajadores y veraneantes de Punta del Este y un mapa de bienes culturales y de la memoria con información (narrativas, textos, fotos, audios y videos) vinculada por medio de un código $\mathrm{QR}^{1}$.

El objetivo de este artículo es reflexionar sobre el devenir de la activación y puesta en valor de bienes culturales/patrimoniales de la península de Punta del Este y presentar los resultados obtenidos con el proyecto. Se espera que los productos desarrollados contribuyan a la diversificación de la oferta y la integración del ocio y conocimiento, teniendo en consideración que la tradición de Punta del Este está vinculada al modelo turístico de sol y playa.

\section{MARCO DE REFERENCIA DE LA PUESTA EN VALOR TURÍSTICA DE LOS BIENES CULTURALES}

Los bienes culturales y patrimoniales pueden ser considerados como una categoría de pensamiento situada entre el pasado y el presente (Gonçalves, 2003), un importante campo de investigación, dado que sus sentidos y significados son construidos socialmente (Prats, 2005; Poulot, 2008), por eso se hace necesario tener en cuenta la diversidad de sus representaciones y la importancia que tienen para determinados grupos y comunidades, en el proceso de fortalecimiento de las identidades locales y del sentido de pertenencia (Funari y Pelegrini, 2009).

Según Arantes (2006), el patrimonio resulta del acto de preservar. Por esta razón, la tensión generada entre los significados arraigados en las prácticas de los grupos sociales que los mantienen en sus contextos originales, y los atribuidos por las agencias institucionales, se convierte en constitutiva del bien patrimonial. Tal como afirma Tamaso (2007), hay elementos cotidianos que, a pesar de ser forjados como elementos de identidad, no siempre están protegidos por acciones de preservación y, al mismo tiempo, no todos los bienes culturales seleccionados por las instituciones de preservación son apropiados por los residentes. En ese sentido, es pertinente hacer referencia a la categoría de resonancia utilizada por Gonçalves (2003), que sería el poder de evocar la identificación, la noción de pertenencia y afecto de las comunidades.

${ }^{1}$ Del inglés Quick Response code, «código de respuesta rápida». 
En contrapartida, Cornelius Holtorf (2006) afirma que algo que no se puede preservar fácilmente es la razón de la preservación del patrimonio cultural. Para el autor, si el patrimonio debe ser problematizado a través de la lente de la diferencia cultural, los conceptos relacionados con la antítesis de conservación y destrucción también deben ser repensados. El ataque del 11 de septiembre de 2001 contra las torres gemelas del World Trade Center en Nueva York es un ejemplo. Según Holtorf (2006), las torres gemelas, antes del atentado, no eran consideradas obras maestras arquitectónicas ni eran extremadamente importantes para los neoyorquinos. Pero debido a su pérdida, han adquirido nuevos significados, «si se dice que el patrimonio contribuye a las identidades de las personas, la pérdida del patrimonio puede contribuir a las identidades de las personas aún más» (Holtorf, 2006, p. 103). En este sentido, la destrucción y la pérdida no serían lo contrario del patrimonio, sino parte de su propia sustancia, así como la relación entre la memoria y el olvido.

En las últimas décadas, los bienes culturales han devenido objeto de interés turístico. En la actualidad muchas personas se desplazan para conocer, apreciar y relacionarse con diversos bienes culturales de diferente orden e interés: arquitectónico, histórico, museístico, paisajístico arqueológico, paleontológico, culinario, industrial, etc.

La actividad turística puede repercutir positivamente sobre dichos bienes contribuyendo a su preservación y protección, y puede también generar beneficios económicos para los territorios, siempre y cuando haya un sistema de planificación y gestión del uso turístico en estos espacios.

Asimismo, existe una amplia bibliografía que aborda los impactos negativos del uso turístico de los bienes culturales y patrimoniales (Prats, 2005; Almirón et al., 2006; Poulot, 2008; Bertoncello 2008, 2019; Santana Talavera, 2009). Algunas de las problemáticas estudiadas tienen que ver con las consecuencias de la rehabilitación de edificios o lugares, así como con el desplazamiento de residentes en función de la especulación inmobiliaria. También es posible encontrar estudios de caso que trabajan la descaracterización de los bienes materiales e inmateriales en la búsqueda de la autenticidad o de la escenificación.

Sin embargo, algunos problemas se manifiestan antes del uso turístico y tienen que ver fundamentalmente con el proceso inicial de identificación y activación de los bienes culturales y patrimoniales. Tal como afirma Meneses (2006), el patrimonio es un campo de disputas y conflictos donde ocurre la emergencia de diversos intereses y no todos ellos van en el mismo sentido.

El investigador argentino Rodolfo Bertoncello $(2008 ; 2010)$ busca entender cuáles son los patrimonios que valora el turismo, porque para él, no todo el patrimonio entra en la lógica turística. También busca comprender cuáles son los intereses y expectativas que guían la selección de un bien en particular, para transformarlo en una atracción turística. Una ciudad histórica tiene diferentes edificios, y ¿por qué solo unos pocos lugares se convierten en atracciones?

La elección de los bienes culturales que serán transformados en productos y/o atractivos turísticos, de una región o ciudad, es un proceso que involucra a diferentes actores y sectores del sistema turístico, pero está principalmente relacionado con las políticas públicas. En algunos casos, se percibe que hay una falta de coinci- 
dencia entre la imagen turística de un territorio, utilizada en su promoción, y lo que constituye el conjunto de símbolos, significados y costumbres de una comunidad. De acuerdo a Calle Vaquero (2006), eso ocurre porque los recursos turísticos están relacionados con la identidad turística, conformada por discursos más sencillos y asequibles a públicos que no siempre comparten el sustrato cultural local, mientras que las identidades locales son siempre más complejas. Esto lleva a pensar que para incluir aspectos vinculados a la cultural local, su historia y memoria en la identidad turística, es necesario comprender y conocer en profundidad sus características y componentes, mediante investigaciones y, sobre todo, trabajar en conjunto con diferentes actores mediante procesos participativos.

El investigador español Llorenç Prats (2009, p. 164) plantea algunos requisitos metodológicos básicos, vinculados a investigación de bienes culturales: el compromiso para elaboración de un proyecto aplicado solo puede establecerse sobre las bases de un conocimiento profundo de la realidad sociocultural y de los intereses y motivaciones reales de los distintos actores sociales, los resultados de estas experiencias deben hacerse públicas y finalmente, cualquier activación patrimonial debe ser planteada y explicada desde la lógica de los intereses turísticos y de la construcción identitaria y nunca al revés.

\section{LA PENÍNSULA DE PUNTA DEL ESTE: ENTRE LA NOSTALGIA Y EL DESARROLLO INMOBILIARIO}

El municipio de Punta del Este está ubicado en el departamento de Maldonado, en el sureste de la República Oriental del Uruguay. Este departamento posee costas tanto sobre el Río de la Plata, como también sobre el océano Atlántico, factor sustancial, que ha facilitado que esta zona sea considerada actualmente uno de los principales corredores turísticos del país.

El balneario, representado icónicamente por la escultura «Los dedos» 0 «La Mano» y asociado a Casapueblo en Punta Ballena, a las playas, los casinos y las fiestas, ha logrado posicionarse en el mercado como uno de los principales destinos turísticos de América Latina (Campodónico y Zorzi, 2019).

Desde hace más de 30 años, frente al intenso desarrollo inmobiliario, grupos de antiguos residentes y veraneantes, sociedades de arquitectos y facultades de arquitectura de Uruguay y Latinoamérica se han venido movilizando con el fin de preservar determinados bienes y lugares. Específicamente en la península, en 1986 se forma el grupo Amigos del Faro, que desde entonces actúa en la preservación del faro y su entorno. También existe un grupo formado principalmente por exalumnos de la Escuela Pública n. ${ }^{\circ}$ 5, que lograron la preservación del edificio de la exestación de expendio de combustible de Ancap, en la emblemática calle Gorlero, y la restauración del Muelle de Mailhos en la Playa Mansa. En relación con otros lugares próximos a la península, recientemente, grupos locales y sociedades de arquitectos y facultades de Arquitectura de Uruguay y Latinoamérica se manifestaron en contra de la demolición del antiguo Hotel San Rafael, ubicado en el barrio del mismo nombre. También reivindicaron la preservación de Solana del Mar, construcción 
ubicada en Portezuelo, obra del arquitecto Antonio Bonet, y la casa Poseidón, del arquitecto Samuel Flores.

En relación con la protección jurídica, de acuerdo a la Comisión del Patrimonio Cultural de Uruguay, en el departamento de Maldonado actualmente existen 36 bienes considerados Monumentos Históricos Nacionales, de los cuales tres están ubicados en Punta del Este, a saber: el Faro de Punta del Este, la exestación de Ancap y el edificio de la Aduana. En el año de 2009, fue creada en el departamento la Comisión de Patrimonio Histórico, Cultural y Natural, con el cometido, según el Decreto 3844, de 2008, de «Asesorar al Municipio en el señalamiento de los bienes a declararse de interés patrimonial, desde el punto de vista histórico, artístico, cultural y natural». Con la creación de dicha comisión, algunos bienes fueron reconocidos de interés patrimonial, como "Las Mesitas», lugar de socialización y contemplación en la orilla de la Playa Brava en Punta del Este. A su vez, el municipio cuenta con una comisión de Cultura y Patrimonio que asesora a los concejales de la Alcaldía en la toma de decisiones vinculadas a cuestiones culturales del balneario.

Más allá del empeño en la preservación de lo tangible, es posible observar también un interés en los antiguos moradores de Punta del Este en recordar el pasado, ya sea en eventos sociales, como el «homenaje a los antiguos residentes y veraneantes», o en grupos de Facebook, como "De la Punta de Punta Soy». En estos espacios, a través de los relatos, emerge la nostalgia de una época en la que todos se conocían y se encontraban en lugares tradicionales, como la panadería de la esquina o los cines del barrio. Se expresa también el sentimiento de que algo se perdió y que no volverá a ser lo que era.

Actualmente, la horizontalidad preservada del paisaje se encuentra en la zona portuaria y del faro, en la punta de Punta del Este (península), considerada por la población local como el barrio histórico, dado que allí se encuentran algunas de las construcciones más antiguas de la ciudad, tales como el faro, la aduana, el puerto, antiguos hoteles, restaurantes, club, etc. En ese sentido, el contraste entre lo moderno, representado por los edificios lujosos, y lo antiguo, lo histórico, lo horizontal, se nota a la distancia en el paisaje.

En tanto histórico, relacional e identificatorio, puede considerarse a la península como lugar antropológico (Augé, 2000). Además de ello, es un lugar imaginado, y en tanto sobre él se tejerán varias miradas y discursos provenientes de diversos lugares sociales y espaciales. A todo esto, por su carácter de 'destino', también puede considerarse a la península como 'Lugar Turístico', pautado en gran medida por diversas dinámicas de estacionalidad. En este lugar antropológico que es a su vez lugar turístico, el espacio urbano y su patrimonio, se habilita la emergencia de memorias que contribuyen a su vez a configurar distintas formas de representar la ciudad, de recorrerla, de apropiarla y de imaginarla.

En ese sentido, y tal como veremos a continuación, es posible afirmar que existe un interés de la comunidad y de algunas organizaciones y de autoridades locales en preservar determinados lugares y registrar memorias asociadas a Punta del Este. 


\section{EL PROCESO DE IDENTIFICACIÓN DE BIENES CULTURALES Y REGISTRO DE MEMORIAS}

En el año 2016, la Comisión de Cultura y Patrimonio del Municipio de Punta del Este se contactó a la coordinación de la carrera "Licenciatura en Turismo» del Centro Universitario de la Región Este (CURE) de la Universidad de la República (UDELAR), manifestando interés en desarrollar un proyecto en común. El objetivo planteado fue la identificación y registro de los bienes culturales de la península de Punta del Este, así como generar propuestas que pudieran conducir a la elaboración de productos o servicios turísticos concretos.

Las actividades de investigación estuvieron pautadas por la utilización de una metodología cualitativa, proveniente de la tradición antropológica en general y etnográfica en particular, en interfaz con el trabajo de investigación en turismo.

Se realizó primeramente una búsqueda de antecedentes, donde fue posible identificar trabajos que se han concentrado fundamentalmente en el proceso de institucionalización del turismo en Punta del Este, la coyuntura social, política y económica que influenció su desarrollo (Trochón, 2017), el análisis de la comunicación y creación de la imagen (Campodónico y Da Cunha, 2009) y el proceso de transformaciones y dinámicas territoriales de la región (Leitch, 2012; Roche, 2015).

Además de la investigación bibliográfica, entre 2016 y 2019 fueron realizadas observaciones, principalmente en eventos locales, como el homenaje a antiguos residentes y veraneantes, registros audiovisuales y veintiuna entrevistas (21) en profundidad, a trece antiguos y actuales residentes de la península, algunos nombres fueron sugeridos por la Comisión de Cultura y Patrimonio y otros fueron indicados por los propios entrevistados. Estas entrevistas estuvieron centradas en el registro de narrativas asociadas a la historia de la ciudad, en la identificación de lugares valorados por los entrevistados y percepciones del presente referentes a temas como turismo, turistas, migración y cultura.

Las personas entrevistadas fueron en su mayoría antiguos residentes de Punta del Este, con edades entre los 70 y los 90 ańos. El corte socioeconómico del grupo es de clase media-alta. El trabajo con este grupo y el registro de sus memorias se ha revelado como importante para la comunidad ${ }^{2}$, pues debido a la edad de sus integrantes algunos han fallecido en el tiempo de desarrollo de la investigación.

Las entrevistas fueron sistematizadas y se definieron categorías y subcategorías de análisis, tales como acontecimientos, lugares, personas, prácticas y saberes y oficios. En cuanto a los lugares considerados importantes para las personas entrevistadas, prevalecieron los relacionados a la oferta de servicios turísticos del pasado como hoteles y restaurantes; espacios de socialización y recreación, como

2 Dado el interés de la comunidad en la temática, en conjunto con la Comisión de Patrimonio del Municipio fueron realizadas dos ediciones (2017 y 2018) del evento Panel de la Memoria, en ambas actividades hubo una expresiva participación de los antiguos residentes. En esas actividades tres personas referentes locales fueron invitadas a compartir sus recuerdos y vivencias. 
la escuela, y algunas de las construcciones más antiguas, como el faro y la aduana, por citar algunos ejemplos.

Posteriormente, se procedió a la georreferenciación de los lugares identificados en un mapa en papel $^{3}$ y luego a un mapa digital por medio de la herramienta de Google «My Maps» .

\section{LA PRODUCCIÓN DE MATERIALES MULTIMEDIA CON FINES TURÍSTICOS PARA LA ACTIVACIÓN Y PUESTA EN VALOR DE BIENES CULTURALES/PATRIMONIALES}

Ante la necesidad de continuar el proceso de investigación y dar a conocer los resultados del mismo, en el año 2020 se elaboró el proyecto «Activación y puesta en valor de bienes culturales/patrimoniales de la Península de Punta del Este: producción de materiales multimedia con fines turísticos». Su ejecución tuvo lugar entre los meses de junio y diciembre y contó con el apoyo financiero del Departamento de Ciencias Sociales y Humanas (DCSH) del CURE y del Municipio de Punta del Este.

El proyecto contempló la integralidad de las funciones universitarias (enseñanza, extensión e investigación), por lo tanto, fueron propuestos diferentes objetivos. Las actividades de enseńanza tuvieron como cometido problematizar los bienes culturales identificados desde la óptica patrimonial y turística, mediante la realización de trabajos prácticos en el curso Antropología del Turismo.

El objetivo vinculado a la extensión estaba centrado en dar continuidad al trabajo realizado anteriormente, a través de la creación de instancias de participación de esos grupos en la definición de lo que consideran bienes culturales y en los contenidos asociados a ellos. Por otro lado, se propuso la creación de materiales informativos y de difusión de los lugares identificados, con el fin de disponibilizar al público (comunidad local y visitantes) los resultados de la investigación y activar turísticamente los bienes identificados. Estos productos son una serie de videos documentales cuyos protagonistas son antiguos residentes, trabajadores y veraneantes de Punta del Este y un mapa de bienes culturales y de la memoria con información (narrativas, textos, fotos, audios y videos) vinculada por medio de un código QR.

Las actividades de investigación tuvieron como objetivo generar conocimiento sobre cada bien cultural identificado en la investigación previa, con el fin de contar con insumos para la creación del material multimedia. Para tal fin, fueron utilizadas fuentes primarias (entrevistas realizadas por el equipo en etapas anteriores) y fuentes secundarias (revisiones bibliográficas, documental y búsqueda de imágenes).

${ }^{3}$ En el proceso, surgieron dudas sobre la ubicación de algunos bienes culturales. Fue necesario consultar a antiguos residentes, así como un mapa de vecinos y comercios creado por Luis Sáder.

${ }^{4}$ Para visualizar el mapa ingrese al enlace https://www.google.com/maps/d/u/0/edit?mi$\mathrm{d}=1$ BsoTET4nJGU2BKRzMsGshXWNp7XXmSBa\&usp=sharing. 

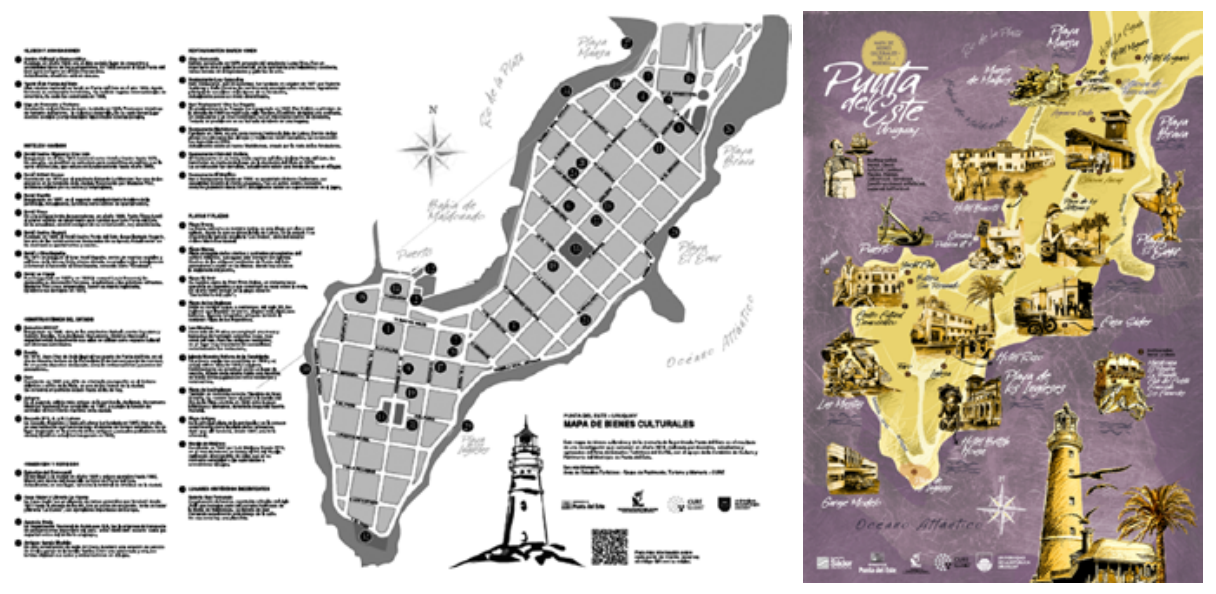

Imagen 1: Mapa de Bienes Culturales de la península de Punta del Este.

Fuente: elaboración propia.

La realización del proyecto ocurrió en tres etapas. Primeramente, se realizaron una serie de reuniones con representantes de la Comisión de Cultura y Patrimonio de Punta del Este, institución con la cual se venía trabajando desde el año 2016, con el objetivo de presentar el proyecto y solicitar apoyo para realización del mismo. En la primera etapa se retomó el trabajo de geolocalización de los lugares identificados y se realizó un prototipo de un mapa de la memoria y de los bienes culturales de la península de Punta del Este. En total, fueron ubicados treinta y cinco (35) lugares de interés, esos lugares son antiguos comercios y servicios turísticos (hoteles, casinos, restaurantes y bares); construcciones estatales (escuela, faro, puerto y aduana); y espacios de sociabilización (club, asociaciones, plazas y playas).

Posteriormente, fueron realizadas visitas en el área delimitada, con el fin de constatar la viabilidad del uso turístico del mapa prototipado, fueron considerados algunos aspectos como distancias, tiempo de traslados ${ }^{5}$, estado de conservación del bien o inexistencia de vestigios materiales, elementos perceptibles, entre otros aspectos.

Una vez validado el mapa se continuó con la redacción de una breve reseña de hasta trescientos (300) caracteres para cada lugar de interés, con el fin de proporcionar más información instantánea al visitante; paralelamente, se buscaron referencias gráficas para el diseño del mapa ${ }^{6}$. Se optó por la realización de un mapa plegado, con una parte funcional en blanco y negro y otra artística en formato póster (imagen 1).

5 Importante resaltar que el mapa no sugiere recorridos o itinerarios.

\footnotetext{
biliaria Sáder.

${ }^{6}$ El diseño del mapa fue realizado por Hugo Baratta, contó con el patrocinio de Inmo-
} 
Dadas las limitaciones de espacio en el mapa impreso, se optó por incluir en el diseńo un código QR con acceso a una carpeta en la plataforma Google Drive ${ }^{7}$, para que el visitante pudiera encontrar más información sobre cada punto de interés. Se eligió mostrar esa información por medio de diferentes recursos (audio, video, texto). Primeramente fueron revisadas todas las entrevistas realizadas en el marco del proyecto con el fin de recortar fragmentos de audios referentes a los bienes culturales identificados. Estos fragmentos constituyen anécdotas, explicaciones, narrativas sobre esos lugares. Fueron omitidos aquellos pasajes donde el entrevistado solicitó confidencialidad.

Dada la inexistencia de información online sistematizada sobre la mayoría de los bienes culturales identificados se optó por la realización de textos con fotos sobre algunos de los puntos de interés. En esta fase, se realizó relevamiento bibliográfico, consulta en portales de internet, foros y grupos de Facebook, y análisis de las entrevistas realizadas en el marco del proyecto. También se buscaron imágenes antiguas relativas a cada bien (fachada, elementos internos, menús de restaurantes, acontecimientos, personas vinculadas, etc.). En esta etapa, los estudiantes del curso de Antropología del Turismo también fueron invitados a publicar sus trabajos de fin de curso, cuya consigna estaba centrada en los bienes culturales de la península.

En esta etapa también fueron producidos quince (15) cortometrajes sobre algunos de los bienes culturales identificados. La realización de este contenido contó con el apoyo del Municipio de Punta del Este, mediante la contratación de un equipo técnico especializado en producción audiovisual ${ }^{8}$. Durante todo el proceso, se concretaron varias reuniones entre el equipo académico, técnico y representantes del Municipio de Punta del Este, a fin de planificar y coordinar las actividades.

Tal como fue mencionado anteriormente, se seleccionaron quince lugares (15) del total de treinta y cinco (35) presentes en el mapa. La selección se basó en criterios como existencia de personas que pudiesen hablar o contar historias sobre esos lugares y disponibilidad de material previo.

Una vez seleccionadas las personas que serían entrevistadas se elaboraron las pautas de entrevistas para la grabación, teniendo en cuenta el material de la investigación previa, y se definieron locaciones para cada entrevista ${ }^{9}$. En total fueron grabadas diez (10) personas, antiguos residentes, trabajadores y veraneantes de Punta del Este; algunas de estas personas ya habían sido entrevistadas en la primera fase del proyecto, facilitando así la elaboración de las preguntas para la grabación del video (imagen 2).

El resultado de este proceso se constituye en una serie de quince (15) videos titulada «Bajo la Arena: Memorias de Punta del Este», nombre que alude al intenso desarrollo inmobiliario de las últimas décadas, y a la supervivencia de la memoria

7 Para acceder al contenido ingrese en el siguiente enlace: https://drive.google.com/drive/ folders/0B8okD1YCdzIAZGxNdUx2M3hObWc?usp=sharing.

${ }^{8}$ Equipo técnico realizador: Incógnita Multimedia.

9 El rodaje de la serie ocurrió entre los meses de agosto y diciembre de 2020; dada la situación sanitaria del país y del mundo, se tomaron todas las medidas de prevención de contagio del Covid-19. 


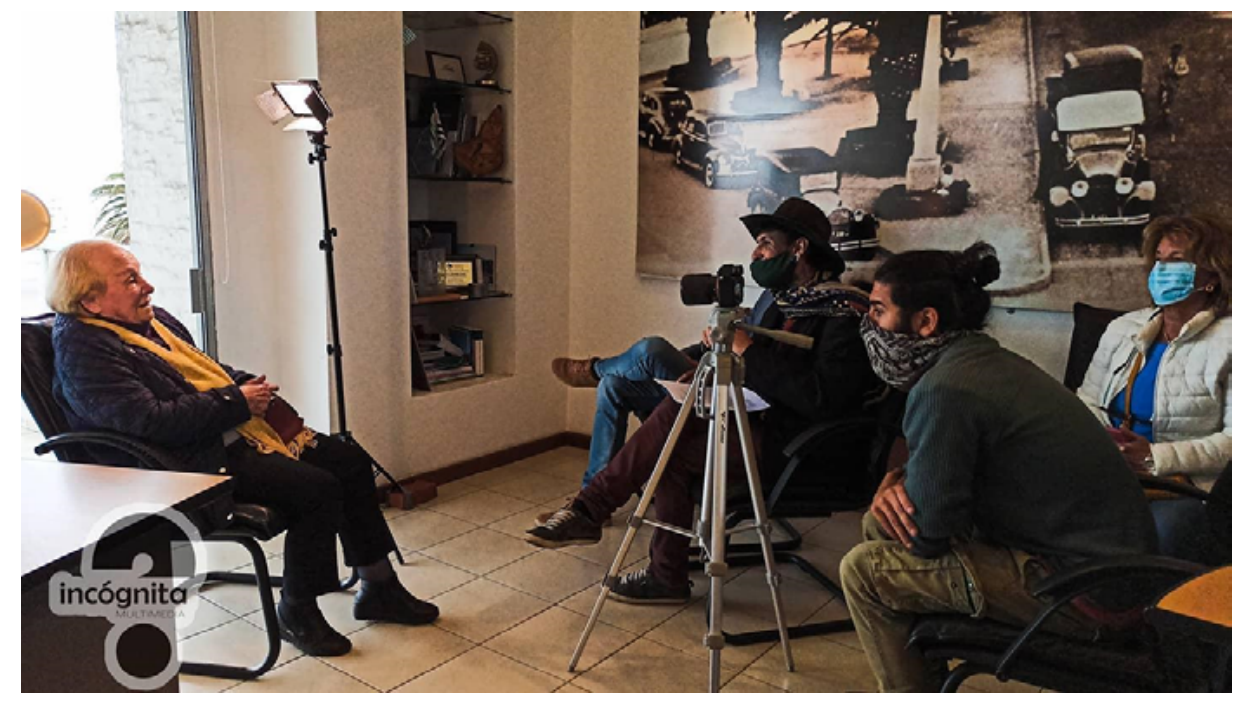

Imagen 2: Rodaje de la serie.

Fuente: Incógnita Multimedia.

de los antiguos residentes. La miniserie fue transmitida en el mes de julio de 2021, a través del canal del Estado, Televisión Nacional de Uruguay. Posteriormente los capítulos serán publicados en redes sociales, como Facebook y YouTube ${ }^{10}$, y en la carpeta alojada en Google Drive. En general, la miniserie fue muy bien valorada tanto por los protagonistas como por el público. Existe interés de algunas personas en participar de futuras instancias de registro de narrativas, y se recibieron sugerencias de continuar la serie, abordando otros lugares de la península y de Punta del Este.

\section{CONSIDERACIONES FINALES}

El proceso de identificación de bienes culturales y registro de memorias de la península de Punta del Este, realizado entre los años de 2016 y 2019, ha sido una experiencia de aprendizaje, intercambio y reflexión, donde participaron estudiantes, egresados, docentes, sociedad civil y actores políticos/institucionales. A partir de este trabajo se constató la necesidad de los antiguos y actuales residentes de la península en dar a conocer sus bienes culturales, mantener presentes sus memorias e historias y los lugares patrimoniales materiales que aún existen. Por otro lado, ante la ausencia

10 Para ver los videos ingrese al siguiente enlace: https://www.youtube.com/channel/ UCjtsTbhd-EKNIEl7tFyzsNA/featured. 
de algunos de los bienes culturales identificados en la oferta turística de la ciudad, se realizaron acciones concretas para la activación y preservación de la memoria colectiva local mediante la elaboración de un mapa y contenidos multimedia.

Es posible afirmar que existe una memoria compartida que delinea los trazos de una Punta del Este pasada y reivindicada por los locales como ideal. En términos de una de las entrevistadas, «aquella Punta del Este nos espera debajo de esta", expresando la idea de que bajo el hormigón y los grandes edificios hay, por una parte, una ciudad distinta (que parcialmente pertenece al pasado), y que traída a través de la memoria se hace presente en un hoy transfigurado y aporta a una posible proyección futura del lugar: «nos espera», fue, y, a la vez, puede volver a ser (Campodónico y Zorzi, 2019).

Todos los lugares identificados como importantes para estos grupos locales están asociados a acontecimientos, prácticas, usos y relaciones, reforzando así el sentido de la península como lugar antropológico (Augé, 2000). Por otra parte, el sentido atribuido a estos lugares transmite la inmaterialidad de los bienes, independientemente de la existencia material de ellos en el presente. Es importante resaltar que la mayoría de esos lugares o las narrativas que emergen a partir de ellos no son parte de la oferta turística de la ciudad, ya sea como circuitos temáticos o emprendimientos privados, lo que nos remite al cuestionamiento de Rodolfo Bertoncello (2008; 2010) respecto de la inclusión/exclusión de determinados bienes en la lógica turística.

En ese contexto, es posible aplicar la diferencia entre identidad turística e identidad local apuntada por Calle Vaquero (2006). También es pertinente retomar algunas de las características del patrimonio cultural como recurso turístico apuntadas por Azevedo (2002), a saber: los bienes y servicios culturales no son necesariamente turísticos y algunos de ellos tienen, como propietarios y administradores, personas u organismos que no siempre muestran interés ( $\mathrm{y}$ a veces incluso se oponen) a mantener actividades turísticas vinculadas a este patrimonio.

Tal como fue mencionado anteriormente, la península de Punta del Este pasó por un intenso proceso de desarrollo inmobiliario y turístico que tuvo como consecuencia la demolición de algunos lugares o la transformación del paisaje (el caso más reciente, la demolición del Hotel San Rafael, ícono del balneario) reforzando aún más el sentido de pertenencia de la población local a determinados lugares (Holtorf, 2006). Esto ha despertado reflexiones y debates en el propio proceso de investigación: ¡cómo poner en valor y activar bienes que ya no existen materialmente en el presente, ¿qué criterios considerar a la hora de seleccionar qué entra y qué no entra en un mapa turístico basado en lugares que son bienes culturales y patrimoniales?

Otra reflexión tiene que ver con la diversidad de recursos y herramientas que se pueden utilizar para la difusión y activación turística de los bienes culturales, como son las redes sociales, los mapas interactivos y las plataformas gratuitas de almacenamiento de información. Sin lugar a dudas las Humanidades Digitales son una importante área a explorar. Por otro lado, entendemos que en un destino como Punta del Este, donde la principal atracción es la playa y el aire libre, la inclusión de materiales como el mapa y su contenido contribuye a integrar ocio y conocimiento y a diversificar la oferta. 
En el proceso de producción de material multimedia fue posible constatar la importancia de contar con conocimientos especializados en otras áreas además del turismo, historia y antropología, como por ejemplo producción audiovisual y diseño gráfico. También fue de suma importancia contar con el conocimiento y la red de contactos disponibilizada por integrantes de la Alcaldía de Punta del Este, que formaron parte principalmente del proceso de producción audiovisual.

Tanto en la fase de investigación como en la producción de materiales de difusión, estuvo presente la reflexión acerca de la selección de las personas entrevistadas y en consecuencia de los lugares indicados como importantes, desde el punto de vista cultural y de la memoria social. Seleccionar referentes y narrativas es un proceso que requiere de cuidado y responsabilidad y, sobre todo, la participación de personas pertenecientes a diferentes grupos.

En este sentido, uno de los desafíos que se nos presentaron fue incluir la diversidad de identidades y de memorias socialmente compartidas, en poco tiempo y con pocos recursos. Sin lugar a dudas, la identificación y el registro de bienes culturales es un trabajo que necesita continuar. La memoria como construcción social viva, entre el pasado y el presente, es un proceso constante que no termina en la configuración de narrativas de un conjunto de actores, sino que se construye mediante espacios de participación colectiva que retroalimentan los significados de los bienes patrimoniales. Este mapa de bienes culturales y de la memoria no es un fin en sí mismo, es apenas el inicio de un espacio abierto para sumar nuevas narrativas, registrar historias y poner en valor lugares importantes.

\section{AGRADECIMIENTOS}

Esta investigación fue posible gracias al apoyo del Departamento de Ciencias Sociales y Humanas del Centro Universitario Regional del Este (CURE, UdelaR). El trabajo que viene realizándose desde 2016, ha contado con la colaboración del Municipio de Punta del Este, en particular de su Comisión de Cultura y Patrimonio. Se agradece la participación en este proceso de docentes, estudiantes y egresados de la Licenciatura en Turismo del CURE.

Por último, este trabajo no hubiera sido posible sin la participación de las personas que accedieron a ser entrevistadas. A todos ellos, nuestro agradecimiento. 


\section{BIBLIOGRAFÍA}

Almirón, A., Bertoncello, R. y Troncoso, C.A. (2006). Turismo, patrimonio y territorio: Una discusión de sus relaciones a partir de casos de Argentina. Estudios y perspectivas en turismo, 15(2), 101-124.

Arantes, A. (2006). «O Patrimônio Cultural e seus usos nas cidades contemporâneas», en V. Mori, M. Souza, R. Bastos y H. Gallo (comps.), Patrimônio: Atualizando o Debate. 9a Sr/Iphan.

Augé, M. (2000). Los No Lugares. Espacios del anonimato. Una Antropología de la Sobremodernidad. Ed. Gedisa S.A.

Azevedo, J. (2002). «Cultura, patrimônio e turismo», en M. Irving, Turismo: o desafio da sustentabilidade. Futura.

Bertoncello, R. (2008). Turismo y geografía. Lugares y patrimonio natural-cultural de la Argentina. Ediciones CICCUS.

Bertoncello, R. (2010). «Turismo y patrimonio, entre la cultura y el negocio», en M. Paes y M. Oliveira (comps.), Geografia, turismo e patrimônio cultural. Annablume.

Calle Vaquero, M. (2006). La ciudad histórica como destino turístico. Editorial Ariel, S/A.

Campodónico, R. y Da Cunha, N. (2009). «Mar del Plata y Punta del Este entre la permanencia y la renovación». Estudios y Perspectivas en Turismo, 18(5), 606-623. https://www.estudiosenturismo.com.ar/PDF/V18/v18n5a6.pdf.

Campodónico, G., Zorzi, M. y Bianchi, F. (2019). «Entre turistas y locales: desafíos asociados a procesos de identificación y puesta en valor de bienes culturales/patrimoniales intangibles». Actas de las Jornadas Académicas FHCE. http://www.jornadas.fhuce.edu.uy/images/2019/ Ponencias_completas/GT_23_-_Campod\%C3\%B3nico_Zorzi_y_Bianchi.pdf.

Campodónico, G. y Zorzi, M. (2019). «De lo inhóspito al glamour: narrativas sobre las transformaciones de Punta del Este, Uruguay, en la mirada de los antiguos residentes». Rosa dos Ventos -Turismo e Hospitalidade, 11(2), 236-25. http://dx.doi.org/10.18226/21789061.v11i2p236.

Funari, P.P.A. y Pelegrini, S.C.A. (2009). Patrimônio histórico e cultural, 2. ${ }^{a}$ ed. Jorge Zahar Ed.

Gonçalves, J.R.S. (2003). «O patrimônio como categoria de pensamento», en R. Abreu y M. Chagas (org.). Memória e patrimônio: ensaios contemporâneos. DP\&A: Faperj: Unirio.

Holtorf, C. (2006). "Can less be more? Heritage in the Age of Terrorism». Public Archaeology, 5 (2), 101-110. https://doi.org/10.1179/pua.2006.5.2.101.

Junta Departamental de Maldonado (2008). Decreto n. ${ }^{\circ} 3844$.

Leitch, E. (2012). «El proyecto territorial del balneario uruguayo: modelos, paradigmas y utopías». Identidades: Territorio, Proyecto, Patrimonio, 3, 293-320. http://upcommons.upc.edu/ revistes/handle/2099/13508.

Meneses, U.T.B. (2006). «A cidade como bem cultural -Áreas envoltórias e outros dilemas, equívocos e alcance na preservação do patrimônio ambiental urbano», en V.H. Mori, M.C. Sousa, R.L. Bastos y H. Gallo (orgs.), Patrimônio: Atualizando o Debate. 9a SR/IPHAN. 240, p. II.

Poulot, D. (2008). «Um Ecossistema do Patrimônio», en C. Carvalho, M. Granato, R. Bezerra y S. Benchetrit (orgs.), Um Olhar Contemporâneo sobre a Preservação do Patrimônio Cultural Material. Museu Histórico Nacional. 
Prats, L. (2005). «Concepto y gestión del patrimonio local». Cuadernos de Antropología Social, 21, 17-35. http://revistascientificas.filo.uba.ar/index.php/CAS/article/view/4464/3967.

Prats, L. (2009). Antropología y patrimonio. 3. a edición. Ariel.

Roche, I. (2015). Modalidades de ocupación del litoral atlántico uruguayo. VII Seminario Internacional de Investigación en Urbanismo, Barcelona-Montevideo, junio 2015. Barcelona, DUOT. http://hdl.handle.net/2117/81052.

Santana Talavera, A. (2009). Antropologia do turismo: analogias, encontros e relaçôes. Tradução de Eleonora Frenkel Barretto. São Paulo: Aleph (Série turismo).

Tamaso, I. (2007). «Relíquias e Patrimônios que o Rio Vermelho Levou...», en M. Filho; C. Eckert y J. Beltrão (orgs.), Antropologia e Patrimônio Cultural. Diálogos e Desafios Contemporâneos. Nova Letra.

Trochón, Y. (2017). Punta del Este. El Edén Oriental (1907-1997). Fin de Siglo. 
